\title{
LETRAMENTOS E ENSINO NO CONTEXTO DA EDUCAÇÃO BÁSICA
}

\section{LITERACYS AND TEACHING IN THE CONTEXT OF BASIC EDUCATION}

\author{
Áustria Rodrigues Brito ${ }^{1}$ \\ Lindalva da Silva Lima²
}

Resumo: Pretendemos refletir o ensino de Língua Portuguesa a partir da experiência de uma professora na Escola Municipal de Ensino Fundamental Prof. Lucíolo Oliveira Rabelo, localizada no interior do estado do Pará, que atende a um público bastante diverso. Adotamos a perspectiva de Street (2014), a qual sugere a utilização do letramento ideológico na escola. Essa abordagem defende que se traga para sala de aula práticas da realidade do aluno, aproximando o conhecimento formal institucionalizado ao conhecimento de mundo do aluno. Dialogamos ainda com Oliveira (2010), que destaca a pluralidade dos letramentos, demonstrando que são dinâmicos e sofrem influências do contexto social em que se desenvolvem. Apoiados nesse pensamento, defendemos que a partir do trabalho com gêneros textuais o professor possa levar os alunos a apropriarem-se de diferentes letramentos. Esperamos que essa reflexão leve a um projeto que vislumbre resultados significativos dentro da perspectiva apontada por Street.

Palavras-chave: Letramentos. Ensino. Gêneros.

\begin{abstract}
We intend to reflect the teaching of Portuguese Language from the experience of a teacher in the municipal elementar school Prof. Lucíolo Oliveira Rabelo, located in the interior of the state of Pará, school that caters to a very diverse students. We adopt the perspective of Street (2014), which suggests the use of ideological literacy in school. This approach advocates bringing classroom pratices to the reality of the student life by bringing istitutionalized formal knowledge to the student's knowledge. We discussed with Oliveira (2010) that highlights the plurality of literacies demonstrating that they are dynamic and undergo influences from the social contexto in which they develop. Based on this thought we defend that from the work whth textual genres the teacher can lead the students to appropriate diferente literacies. We hope that this reflection will lead to a Project that envisions significant results within the perspective pointed out by Street.
\end{abstract}

\footnotetext{
1 A produção deste artigo surgiu a partir de uma discussão inicial realizada na disciplina Alfabetização e Letramento, sob a orientação da Profa. Dra. Áustria Rodrigues Brito. É doutora em Linguística pela Universidade de Brasília (UnB), professora e coordenadora do Mestrado Profissional em Letrasna Universidade Federal do Sul e Sudeste do Pará (PROFLETRAS/UNIFESSPA).É membro do Conselho Consultivo do GELLNORTE (Grupo de Estudos Linguísticos e Literários do Norte).E-mail: austria@unifesspa.edu.br

2 Professora da Rede Pública Municipal de Goianésia do Pará, Pará. É mestranda em Letras pelo programa Profletras na UNIFESSPA (Universidade Federal do Sul e Sudeste do Pará). E-mail: dalvinhachan@ hotmail.com
} 
Keywords: literacy; teaching; genres.

\section{Introdução}

O ensino de Língua Materna - LM, que se iniciou como forma de converter índios pagãos em cristãos e em seguida passou a formar os filhos da aristocracia brasileira, até tornarse um direito universal, vem sofrendo alterações com o decorrer do tempo. Conforme a sociedade muda, as concepções sobre o uso e objetivos da língua também mudam. Uma educação que era para uns poucos indivíduos abastados e que excluía grande parte da população é hoje um direito social indiscutível, devendo, assim, ter todo e qualquer sujeito acesso a ela. Em Goianésia do Pará não é diferente. A EMEF prof. Lucíolo Oliveira Rabelo é mantida pelo governo municipal para que esse direito seja garantido. A escola oferece ensino do $6^{\circ}$ ao $9^{\circ}$ ano, assim como EJA desde a $1^{\text {a }}$ até a $4^{\text {a }}$ etapa, a depender da procura, uma vez que turmas de jovens e adultos não têm tanta procura quanto as do ensino regular dos quatro anos finais do ensino fundamental. Nas turmas regulares, os professores de Língua Portuguesa, juntamente com os de matemática, têm uma carga horária semanal de 6 aulas. São, dessa forma, os professores que mais tempo passam em sala com os alunos, em geral com 3 aulas seguidas, duas vezes por semana. Todo esse tempo ajuda no desenvolvimento do vínculo entre alunos e professores. Como professores de português, temos tempo para conversar e conhecer um pouco da realidade e aspirações de nossos alunos e, assim, podemos perceber o quão heterogêneo é o público que atendemos em cada sala de aula.

Não nos parece possível promover uma educação baseada em estereótipos, que levam a acreditar que nossos alunos são iguais e agem e reagem de forma semelhante a tudo que lhes é apresentado. Acreditamos, assim como Patrick Charaudeau (2015), que a percepção da diferença faz com que julguemos negativamente aspectos do outro que não são semelhantes aos nossos. Sendo nossos alunos sujeitos singulares que interagem em diversas situações e utilizam basicamente a língua para concretizar a interação, a perspectiva de Street (2014, p. 44) do letramento ideológico se faz pertinente, uma vez que reconhece a multiplicidade das práticas sociais. Portanto, nossos alunos são usuários frequentes dos letramentos. A escola tradicional baseada no letramento autônomo trata os alunos como se fossem maquininhas que precisam ser treinadas a responder da mesma maneira aos mesmos estímulos. Esse ensino tem como objetivo o desenvolvimento de competências que são exigidas em exames nacionais de larga escala que medem a qualidade da educação como o Sistema Nacional de Avaliação da Educação Básica - 
Saeb ou em exames de seleção como Exame Nacional do Ensino Médio - ENEM. Esses testes servem para reforçar a necessidade de uma educação que limita o ensino às práticas que levem à mera resolução de questionários e ignora a possibilidade de interpretações alternativas para uma questão.

Street (2014, p. 131) reconhece a importância dos conhecimentos da metalinguística, mas rejeita a alegação de que somente esse conhecimento esteja ligado ao letramento, questionando a ideia de que somente o conhecimento gramatical possa levar à consciência linguística. Ora, questões de leitura e interpretação não dependem fundamentalmente de terminologias gramaticais. Bakhtin (1997) nos esclarece que a estética do texto, por exemplo, é formada pelo leitor: "A partir do nosso ponto de vista, introduziremos na leitura valores que se devem à nossa posição exotópica relativa ao sujeito da introspecção-confissão" (BAKHTIN, 1997, p. 163). A leitura, portanto, é feita, muito mais, a partir de elementos extralinguísticos do que aspectos gramaticais.

Nossos alunos não são uma folha em branco em que imprimimos os conhecimentos formais que levamos para sala de aula, uma vez que carregam consigo conhecimentos e valores sociais que implicam diretamente na forma como leem o mundo, os textos.

Defendemos aqui que o ensino de língua materna não é neutro, imparcial, autônomo, não podendo ser tratado como algo isolado do contexto social do indivíduo. O ensino tradicional afasta a língua dos alunos ao focar em regras gramaticais e suas exceções. Os alunos sentem que a língua que eles estudam não se parece em nada com a língua que usam. Essa ideia é intensificada ao se trazer para sala uma sala de aula do $9^{\circ}$, por exemplo, textos e livros extremamente eruditos, com uma linguagem tão diferente da que os alunos utilizam, inclusive lexical, que os estudantes chegam a julgar que não sabem e não gostam da língua que usam constantemente.

Ensinar por si só é um ato ideológico. Quando interagimos com qualquer pessoa, transmitimos nosso ponto de vista acerca do que é tratado e esse ponto de vista é construído a partir de nosso convívio social. Acreditamos que o ensino baseado no letramento ideológico, considerando que as práticas de uso da linguagem são múltiplas, que não se limitam ao conhecimento metalinguístico, mas se estendem e são influenciadas por aspectos culturais, dêiticos e ideológicos. O ensino que respeita e valoriza a vivência, as práticas locais, pode ser um forte aliado para a formação crítica de nossos alunos. 
Cremos também que em LM devemos trabalhar com diversos letramentos no sentido de “colocar as cartas na mesa" e mostrar que não há uma prática de letramento superior ou melhor que outra, mas que há letramentos melhor aceitos em determinadas situações, conscientizar de que as práticas locais não devem ser menosprezadas, mas que para afirmar a identidade perante uma cultura dominante, que tenta padronizar os seres, é necessário se utilizar dos letramentos dominantes.

Na escola Prof. Lucíolo Oliveira Rabelo, o ensino de Língua Materna não difere da maioria das escolas, uma vez que a prática dos professores é basicamente ligada à imposição de uma só forma "correta" de expressão, as avaliações exigem o uso da linguagem formal e os textos são, em sua maioria, usados como pretexto para cobrar conhecimentos gramaticais. $\mathrm{O}$ letramento autônomo parece não ser foco somente no desenvolvimento dos projetos da escola, nos quais os alunos são levados a realizar atividades com atenção voltada a temas extracurriculares em apresentações para a comunidade escolar em geral, como a comemoração da páscoa, dia das mães, entre outras. Mesmo nesses projetos a linguagem padrão escrita predomina, inclusive nas apresentações orais que geralmente são feitas lendo ou decorando textos escritos. Na sala de aula, assim como na avaliação, o ensino metalinguístico prevalece.

Iniciamos essa reflexão fazendo um breve histórico do ensino de LM no país. Em seguida, mergulhamos nas concepções de Street (2014) acerca dos letramentos e ponderamos acerca da dicotomia letramento autônomo versus letramento ideológico. Partindo deste, consideramos algumas formas de letramentos que consideram o contexto cultural e social dos indivíduos. Por fim, tecemos algumas considerações acerca do uso dos gêneros textuais como ferramenta para alcançar esses diferentes letramentos.

Julgamos que a formação de um cidadão crítico, participativo e capaz de alterar sua realidade social é um objetivo fundamental da escola e, portanto, de todas as disciplinas também. Em especial, temos o caso da LM, pois é por meio do uso da linguagem que os sujeitos conseguem compartilhar suas vivências, refletir sobre e então procurar formas de resolver os impasses que a vida em comunidade nos apresenta. Antunes $(2009$, p. 22) confirma que "[...] a linguagem é o suporte, a mediação pela qual tudo passa de um indivíduo a outro, de um grupo a outro, de uma geração a outra. E é também o meio pelo qual se criam e se instauram os valores que dão sentido a todas as coisas, inclusive o próprio homem.”. Portanto, as experiências vividas, sejam individuais ou coletivas, e os saberes construídos por essas experiências são 
partilhados pelo uso da linguagem, assim como os valores de uma família, de um povo, de uma nação.

Este artigo tem o objetivo de refletir sobre o ensino de LM, visando que os alunos possam desenvolver atividades que aparentemente são difíceis, como a produção de um texto argumentativo dentro de um gênero textual, e que assim percebam as condições que levam a constituição de um texto, bem como dos objetivos e interesses. Dessa forma, objetiva-se que os estudantes possam ser capazes de se posicionar e agir diante de diferentes situações.

Esperamos que com a produção de uma reportagem os alunos sejam capazes de ler não só textos escritos, como também situações e falas. A partir de suas leituras, acreditamos que possam ser capazes de produzir um texto que se enquadre no gênero e ao mesmo tempo revele suas interpretações dos fatos pesquisados.

\section{Breve histórico da educação no Brasil}

A educação no Brasil sofreu inúmeras mudanças desde que foi implantada. Somente no final do Império é que a disciplina Português foi instituída: "é apenas quase no final do Império que as disciplinas retórica, poética e gramática fundiram-se numa só disciplina que então passou a se denominar português" (ROJO, 2009, p. 85). Com ela, ainda segundo Rojo (2009), algumas práticas de gramática e redação perduram no ensino até os dias de hoje, tais como a noção de que só se sai bem nessa disciplina o aluno que tem o dom, uso do texto literário como padrão a ser copiado e com diretrizes a serem seguidas, avaliação centrada em correções gramaticais e ortográficas.

Com o advento da industrialização, muitas mudanças ocorreram na escola. Essa instituição passou a ter uma nova função, que era a de formar mão-de-obra para as indústrias, passando as classes sociais mais baixas a ter acesso à educação. A mudança de objetivo e de clientela muda o ensino, que então se preocupa com questões mais práticas, ligadas à realidade, sendo introduzidos outros gêneros além dos literários nas escolas. Até então o ensino focava nos conteúdos gramaticais.

Na década de 70, alguns estudiosos começaram a criticar essa centralidade do conteúdo. Essas críticas contribuíram para a mudança do currículo, que passou a tratar também dos procedimentos de leitura e produção de texto. Entretanto, o que se verificava era que o texto passou a ser usado como pretexto para continuar trabalhando gramática e ortografia. 
A partir da década de 90, com as novas tecnologias e a globalização, há mais uma vez alteração das necessidades educacionais. Se antes a educação configurava-se em formar mãode-obra para trabalhar nas indústrias, com maquinário, a globalização trouxe a necessidade de saber lidar com a enxurrada de informações que as tecnologias em constante renovação exigiam: "a formação do aluno deve ter como alvo principal a aquisição de conhecimentos básicos (ditos 'competências e habilidades'), a preparação científica e a capacidade para utilizar as diferentes tecnologias relativas às áreas de atuação” (ROJO, 2009, p. 89). A escola se modifica assim como as mudanças sociais demandam. O que inicialmente era usado para enaltecer a cultura das elites hoje é um direito garantido por lei que deve abranger a todos os brasileiros, sendo responsabilidade da escola valorizar também outras culturas:

Art. 205. A educação, direito de todos e dever do Estado e da família, será promovida e incentivada com a colaboração da sociedade, visando ao pleno desenvolvimento da pessoa, seu preparo para o exercício da cidadania e sua qualificação para o trabalho. (BRASIL, 2018 p. 160)

A educação, definida como um direito de todos, deve ser acessível a todo e qualquer brasileiro sem distinção de qualquer esfera, baseando-se, dentre outros, nos seguintes princípios:

I - igualdade de condições para o acesso e permanência na escola; II - liberdade de aprender, ensinar, pesquisar e divulgar o pensamento, a arte e o saber; III - pluralismo de ideias e de concepções pedagógicas, e coexistência de instituições públicas e privadas de ensino; IV - gratuidade do ensino público em estabelecimentos oficiais;(BRASIL, 2018, p. 160)

Portanto, essa educação que abrange a todos deve acontecer em igualdade de condições, permitindo a liberdade de aprender, ensinar e expressar o pluralismo de ideias. A escola como instituição garantidora da educação tem como atribuição assegurar a universalização e o pluralismo de ideias. Mas como fazer isso com um ensino marcado pelo tradicionalismo que enaltece certa cultura em detrimento e/ou até esquecimento de outras? Para que a lei se concretize e a escola pública alcance seus atuais objetivos, é necessário que o ensino não só desenvolva competências e habilidades como também traga para o âmbito escolar as mais diversas práticas sociais. Linguagem é prática social e o ensino de Língua Portuguesa não pode ignorar isso. É necessário que o professor se aproprie dessa concepção e passe a usar mecanismos que tornem o aprendizado significativo para os alunos, levando-os a perceber que já utilizam a língua de forma adequada em situações informais e que precisarão utilizar os ensinamentos da escola para que interagir em situações diferentes daquelas do cotidiano. 


\section{Letramento que silencia}

A educação escolar no Brasil, em geral, tem sido pautada no que Street (2014, p. 52) chama de "letramento dominante". Um determinado grupo de uma determinada cultura por algum motivo, normalmente financeiro, acredita ser superior a outras culturas que possuem menos poder. A classe dominante impõe seus letramentos aos chamados "iletrados" sob o disfarce de valores. Assim, perpetua-se todo um contexto pautado na exploração e submissão de uma classe social: "Em muitas situações, é um grupo dominante dentro de uma sociedade que se responsabiliza por difundir o letramento a outros membros dessa sociedade e a subculturas dentro delas" (STREET, 2014, p. 45). A escola, uma das principais instituições responsáveis pela promoção da educação, dos "bons costumes", vem há muito tempo servindo aos interesses da classe dominante. Pode-se perceber isso quando a escola reforça a chamada cultura de massa que padroniza os seres, fazendo-nos acreditar que precisamos ser iguais para exercermos nossa cidadania e sermos aceitos plenamente na sociedade.

Esse reforço é perceptível quando, por exemplo, nos eventos do dia do "índio" ou da consciência negra não há alunos indígenas ou negros que queiram representar os ícones dessas etnias. Os professores justificam dizendo que os alunos não querem participar. No final das contas, vemos pessoas brancas e magras caricaturadas como pessoas de outra etnia. Nas representações teatrais da páscoa, o aluno que representa Jesus é sempre um branco e magro. A representatividade que se vê dentro da escola costuma ser padronizada:

\footnotetext{
A cultura de massa da globalização é padronizada, monofônica, homogênea e pasteurizada, a ponto de alguns estudiosos da globalização falarem de Mundo Mc, de "mcdonaldização" da cultura, tendo como centro dominante e irradiador o ocidente, branco, masculino, heterossexual, norte-americano: cultura da rapidez, da instantaneidade (fastfood, zapping, clipping) e do excesso (fat food, megalópoles, stress, hipertudo) (ROJO, 2009, p.112)
}

Nossos alunos acabam por crescer e se desenvolver na escola acreditando que devem se enquadrar nesse determinado modelo.

Uma forma única de entender o mundo é imposta desde o currículo, que delimita os conteúdos a serem estudados, ignorando as especificidades de cada lugar, e passa uma visão unilateral dos fatos. Estudantes são silenciados na escola em casos que professores passam atividades exaustivas de cópia, enchendo o quadro de questões e conteúdos, para conseguirem silêncio. O trabalho de língua materna nos anos finais do Ensino Fundamental não pode se limitar a repetições mecânicas do código, afinal, em teoria, o aluno já está alfabetizado, já sabe ler e escrever. Nossos alunos produzem textos constantemente e a interação entre eles é 
permanente, seja em conversas paralelas, em meio à bagunça, participando da aula ou mexendo no celular.

$\mathrm{O}$ ensino deve ser significativo. $\mathrm{O}$ aluno tem que perceber qual a importância do que estuda e se enxergar como capaz de usar esse conhecimento. $\mathrm{O}$ aprendizado que envolve o aluno mostra que ele não precisa estar dentro de um modelo perfeito para conseguir usufruir dos benefícios da educação escolar. $\mathrm{O}$ aprendiz tem o direito de aprender a questionar e assim formular opiniões, se posicionar e se expressar nas mais diversas situações que seu contexto lhe proporcionar. Para isso, acreditamos que o ensino deve abranger as mais diversas práticas de letramento, dando ao aluno o poder de utilizar da linguagem oral ou escrita a seu favor em qualquer situação.

Durante a produção da reportagem o aluno precisa fazer levantamento de dados e julgar o que é relevante ou não para o público que irá alcançar. Apesar de utilizar uma linguagem objetiva, os alunos escolherão pelo menos um ponto de vista para expor. Assim, tratar de assuntos que afetam suas vidas e da comunidade como um todo fará com que pensem em sua realidade e o que gostariam para ela.

Os jovens, hoje, fazem parte de uma geração que se utiliza constantemente das tecnologias digitais, nasceram e estão crescendo em meio a elas. Não faz sentido dizer que uma criança que usa constantemente aplicativos nos celulares como whatsapp e jogos online não sabe ler ou escrever. Encontram-se em constante movimento, se utilizam de diversas práticas de letramentos fora da escola, estão acostumados a acessar várias informações ao mesmo tempo. Eles assistem, por exemplo, ao Big Brother pela TV, votam pelo celular, procuram vídeos na internet com cenas inéditas ou reveem algo e conversam, inclusive na sala de aula, sobre esse programa. Um mesmo tema é abordado e discutido em diversos meios. Mas o ensino parece não acompanhar toda essa efervescência característica da maioria dos alunos.

Enquanto professores, nos desesperamos por não alcançar nossos alunos, por não conseguir fazer o que Bakhtin chama de ponte na interação. Perdemos muito tempo com aulas expositivas em que o professor é o "centro das atenções" e detentor de todo o conhecimento sobre a língua. Os alunos não compartilham desse ponto de vista. Não é à toa que em aulas com esse modelo os aprendizes pouco se envolvem, pouco interagem e pouco aprendem, enquanto que as mídias conseguem envolvê-los, movimentá-los e motivá-los a interagir e participar dos programas. 
A mídia usa seu poder de influência para alcançar os interesses da cultura dominante. Nossos alunos utilizam das tecnologias constantemente e, ao mesmo tempo, disseminam esses valores. Ao ignorar essa dinâmica, a escola perde a oportunidade de fazer os aprendizes refletirem e questionarem as informações e valores que reproduzem de forma automática.

A sociedade evoluiu tecnologicamente, as comunicações são instantâneas, mas o ensino escolar, no geral, se mantém estagnado, limitante. $\mathrm{O}$ aluno é limitado a começar pelos muros e portões da escola, depois por quatro paredes. O espaço do aluno na escola é tão limitado que leis são feitas no sentido de determinar até os metros quadrados a que a criança tem direito. $\mathrm{O}$ Art. $8^{\circ}$ da resolução $n^{\circ} 001$ de 05 de janeiro de 2010 do Conselho Estadual de Educação do Estado do Pará estabelece:

f) estabelecimento do número de alunos por sala de aula observando o índice de metragem de 1,20 m2 por aluno em carteira individual, correspondendo, no mínimo, a 1,00 m2 por aluno, exceção feita à Educação Infantil, para a qual recomenda-se a utilização de $1,5 \mathrm{~m} 2$ por criança atendida em salas de atividades em área coberta; (CEE, 2010, p. 05)

O estudante, em sala de aula, mal tem espaço para se mover e, além disso, na aula poucos são os momentos que dispõe para se expressar. Enquanto isso, sobre os programas de TV, ele se manifesta em/por vários meios. Sobre o texto trabalhado na aula de Língua Portuguesa, por muitas vezes, só lhe é dado alguns instantes, quando ao mesmo tempo em que ouvido é avaliado sob o olhar dos professores. A visão do aluno, o que ele realmente pensa, não costuma ser levado em consideração, principalmente quando se cobra um só modelo de resposta. Nesse sentido, observamos as culturas dominadas, que são colocadas de lado, como meros coadjuvantes no desenvolvimento da sociedade. Se o discente não pode se expressar enquanto pessoa que vive em um determinado lugar, que tem experiências específicas, e se sua vivência não é valorizada, sequer é vista, como esperar que esse ser participe ativamente dessa educação que não o aceita como é?

Lara e Limberti (2015) têm um posicionamento esclarecedor acerca do assunto:

Um dos aspectos mais perversos da segregação diz respeito aos problemas identitários, aos problemas da falta de espaço, aos problemas de preconceito e de intolerância que os indivíduos sofrem e vivenciam. Tal segregação pode ocorrer de forma aberta ou de forma velada. Essa última talvez seja a mais perversa por significar, simulando que não significa. Afinal afirmar que se aceita o outro, mas querê-lo convenientemente a distância, "confinado" em seu "próprio" espaço, não é aceitação real. (LARA, LIMBERTI, 2015, p. 07) 
Portanto, ditar o ensino de determinados letramentos em detrimento da cultura, das práticas sociais dos alunos é segregar, é isolar. Essa dinâmica, se não cria, intensifica os problemas gerados pela não aceitação do outro.

$\mathrm{O}$ acesso à escola vem sendo ampliado cada vez mais, mas ter acesso não garante que os estudantes sejam realmente aceitos pela escola. Quando os letramentos da classe dominante são colocados como superiores de forma velada ou não, há a exclusão, o apagamento de quem não os utiliza. Rojo (2009, p. 113) nos alerta sobre como a indústria cultural intensifica a desigualdade e a exclusão, compactuando, assim, com a diminuição da qualidade de vida das pessoas.

Pensando nessa dicotomia entre o letramento promovido pela escola a tanto tempo e a necessidade de se envolver os aprendizes em um ensino voltado às práticas sociais, Brian Street (2014) divide os letramentos em dois modelos: o autônomo e o ideológico.

O modelo autônomo é aquele tradicional, que vem sendo trabalhado há tempos nas sociedades ocidentais. A maior crítica a esse modelo feita pelo escritor é acerca daquilo que nomeia Grande Divisão. Esse modelo separa a oralidade da escrita, considerando como letramentos somente as práticas relacionadas a esta última. Os chamados "iletrados" seriam aqueles não alfabetizados, predominantemente orais, e suas práticas não estão de acordo com aquilo que a classe dominante preconiza ser determinante para o pleno desenvolvimento tanto dos seres quanto de suas sociedades. Pregam ainda que esse desenvolvimento só pode ser alcançado pelo letramento defendido pela classe dominante. Esse modelo mostra um único caminho para o desenvolvimento, como se o letramento fosse "autônomo", neutro, independente do contexto. A escrita estaria ligada a características que levam a uma evolução, ao crescimento intelectual. Street (2014) deixa claro qual é o posicionamento de alguns autores defensores do modelo autônomo e o que pensam sobre essa dicotomia entre oralidade e escrita:

\footnotetext{
Segundo Ong (e outros autores da mesma linha, como Goody e Olson, discutidos mais demoradamente em outras partes deste livro), o letramento em semelhante sistema de escrita "permite", "facilita", "promove" etc. a mudança de uma mentalidade "prélógica" para uma mentalidade "lógica": a distinção entre mito e história, o florescimento da ciência, da objetividade, do pensamento crítico e da abstração. (Ibidem, p. 165)
}

A escrita seria a única forma de letramento capaz de suscitar o raciocínio lógico e, portanto, é o único letramento admitido de ser trabalhado na escola. A oralidade, por ser instintiva, não lógica, nem racional, não é necessária. 
Consideramos, porém que a oralidade não é inferior à escrita e que aquela exige do ser tanta abstração quanto essa. A escola deve prezar a oralidade tanto quanto a escrita, sendo, por isso, importante que trabalhe com diferentes letramentos no ambiente escolar: "O letramento, agora é evidente, não pode ser separado da oralidade" (Ibidem, p. 187)

Já o modelo ideológico, defendido pelo pensador, considera como letramentos tanto práticas orais quanto as escritas: "Aqueles que aderem a este segundo modelo se concentram em práticas sociais específicas de leitura e escrita. Reconhecem a natureza ideológica e, portanto, culturalmente incrustada dessas práticas" (Ibidem, p. 44). Esse modelo considera o contexto, não isola o letramento como se fosse um só que se desenvolvesse independentemente do contexto social do sujeito: “ideológico' [...] porque ele indica bem explicitamente que as práticas letradas são aspectos não só da "cultura" como também das estruturas de poder" (Ibidem p. 172). Esse modelo não prega uma educação impositiva, silenciosa. Segundo o autor, as práticas culturais são permeadas de ideologia. Como as práticas de letramentos são essencialmente culturais, não há como "neutralizar", isolar o letramento. Ele é ideológico.

\title{
3 Letramentos como práticas sociais
}

As práticas de letramento estão diretamente relacionadas às práticas culturais e são, portanto, inúmeras, já que cada núcleo social tem suas práticas com suas características específicas, seja na família, no trabalho, na escola etc. Rojo (2009) fala sobre letramentos, no plural:

\begin{abstract}
As práticas sociais de letramento que exercemos nos diferentes contextos de nossas vidas vão construindo nossos níveis de alfabetismo ou desenvolvimento de leitura e escrita; dentre elas, as práticas escolares. Mas não exclusivamente. É possível ser não escolarizado e analfabeto, mas participar de práticas de letramento, sendo, assim, letrado de uma certa maneira. O termo letramento busca encobrir os usos e práticas sociais de linguagem que envolvem a escrita de uma e outra maneira, sejam eles valorizados ou não valorizados, locais ou globais, recobrindo contextos sociais diversos (familiar, igreja, trabalho, mídias, escola, etc.) numa perspectiva sociológica, antropológica e sociocultural. (ROJO, 2009, p. 11)
\end{abstract}

Os letramentos são as práticas sociais de leitura e escrita e as práticas escolares são apenas algumas dentro de um mar de diversas práticas. A escola não é a única detentora dos letramentos. Eles acontecem em todo lugar, onde há interação entre pessoas. O que realmente acontece é que alguns letramentos são tão valorizados que acabam por "excluir" os outros, chegando ao ponto das pessoas acreditarem que somente uma forma de letramento é aceitável, útil. 
Baynham (1995 apud OLIVEIRA. 2010, p. 329) vem esclarecer melhor essa multiplicidade quando define os letramentos como múltiplos, dêiticos, ideológicos e críticos.

Os letramentos são considerados múltiplos se considerarmos que são práticas sociais e se considerarmos essas práticas como diversas:

\begin{abstract}
o termo letramento busca recobrir os usos e práticas sociais de linguagem que envolvem a escrita de uma ou de outra maneira, sejam eles valorizados ou não valorizados, locais ou globais, recobrindo contextos sociais diversos (família, igreja, trabalho, mídias, escola, etc.). (ROJO, 2009, p 98)
\end{abstract}

Rojo (2009) não cita as práticas orais que também configuram letramentos, mas não se pode esquecer que a linguagem também se utiliza da oralidade. A pluralidade de práticas sociais de letramento é infinda, ainda mais quando se consideram a oralidade e as práticas do cotidiano. Oliveira (2010, p. 330) chama atenção para o propósito e as funções das práticas de letramento: ““O que' se lê e o 'como' se lê são fortemente determinados pelo 'lugar' de onde lemos.”. Deus, por exemplo, é entendido de maneira diferente dependendo dos preceitos religiosos de cada pessoa. Para um cristão, ele é um só, onipotente e onisciente, mas para um sacerdote malintencionado ele pode representar uma forma de manipular cristãos a fim de manter poder sobre eles. Já para um ateu Deus é uma invenção.

Portanto, a compreensão depende também de onde lemos e o nosso entendimento sobre determinado assunto depende do contexto no qual nos incluímos no momento da leitura. Não é à toa que pessoas diferentes têm diferentes pontos de vista acerca de um mesmo assunto. Nossos alunos são capazes de ler e formar suas opiniões. Assim, nós, professores, temos que levar isso em consideração e não os podar ao exigirmos que assimilem sempre uma mesma interpretação levada por nós para sala de aula.

Leitura e escrita envolvem uma gama de situações e intenções que levam a uma prática ser utilizada em uma determinada situação:

As produções de linguagem de um indivíduo, portanto, efetuam-se, necessariamente, na interação com uma intertextualidade, em suas dimensões sociais sincrônicas e em suas dimensões históricas de traços de construções conceituais e discursivas [langagières] dos grupos sociais precedentes. (BRONCART, 1999, p. 38)

Logo, leitura e produção não são práticas aleatórias e inconscientes. Quando interagimos com o outro, premeditamos e agimos de forma a alcançar nosso objetivo na comunicação. Nesse sentido, quem é o leitor, assim como a forma como o leitor reagirá ao texto, também é pensado e levado em consideração ao produzirmos um texto. Nossos alunos precisam ser sujeitos conscientes de como e onde ler o texto da melhor forma. É preciso que eles transitem pelos mais variados letramentos, que os manipulem a seu favor, tornando-se 
assim cidadãos ativos e não meros ouvintes. Tratar o letramento como único limita o aluno e o faz acreditar que não se encaixa em uma sociedade que só aceita uma mesma forma de se expressar.

Os letramentos são considerados dêiticos, pois o entendimento de determinada situação e/ou palavra varia dependendo do lugar e da época em que for dito, escrito, lido. O termo Quilombo, por exemplo, no princípio de seu surgimento tinha seu sentido ligado à revolta, desobediência, insubordinação dos negros em relação à cultura violentamente opressora: "Os quilombos, deste modo, foram para usar a expressão agora corrente em etnologia - um fenômeno - contra-aculturativo, de rebeldia contra os padrões de vida impostos pela sociedade oficial e de restauração dos valores antigos" (MOURA, 1988, p 11). Hoje, porém, essa mesma palavra tem um sentido diferenciado. Larchert e Oliveira (2013, p. 46) dizem que o termo é "a prática de resistência da cultura afro-brasileira nos dias atuais, que se impõe contra toda forma de discriminação racial e de dominação cultural". Portanto, uma mesma palavra tem seu sentido alterado dependendo da sua localização histórica. Isso não se limita às palavras. Um mesmo texto tem diferentes leituras dependendo da época, do momento histórico em que é lido.

Letramentos são antes de qualquer coisa ideológicos. Toda prática social existe em função de uma conjuntura cultural, com o objetivo, segundo Oliveira (2010, p. 333), de manter ou quebrar paradigmas sociais: "mesmo as concepções que se apresentam como neutras (letramento autônomo), camuflam pressuposições culturais e visões particulares do mundo social, interessadas em sustentar determinadas relações de poder, sendo por isso, ideológicas". Todo sujeito escreve e lê partindo de um contexto histórico: o ser não pode, não conseguiria, ser neutro, pois tudo que pensa está ligado ao contexto em que vive.

Como já dito anteriormente, a escola, em geral, tem uma praxe tradicional, na qual os letramentos de uma determinada cultura são impostos em detrimento de outras, chegando a apagá-las. Essa educação "neutra” acaba por difundir a ideia de que a cultura só existe de uma forma e que, portanto, só são possíveis os letramentos relacionados a ela. Porém, não se pode negar que as culturas locais de diferentes núcleos sociais também são culturas e como tal produzem suas práticas e têm seus letramentos específicos de seus meios. Logo, os letramentos também são culturais.

Os letramentos são críticos no sentido de que formam os indivíduos para não aceitação passiva da cultura dominante: “A teoria crítica está preocupada em entender as relações entre poder e conhecimento e em teorizar o papel da linguagem na produção e reprodução do poder 
na vida cotidiana, na comunidade e nas instituições" (Oliveira, 2010, p. 336). Os letramentos fazem com que o aluno reflita sobre a própria condição e como pode alterá-la ou não, se quer alterá-la ou não.

Freitas (2010) discorre sobre um determinado letramento que é utilizado natural e constantemente por nosso alunado. Com o advento da globalização, avanço e ampliação do acesso às tecnologias, os discentes tornaram-se usuários constantes dos letramentos digitais. Enquanto professores que precisam interagir com os aprendizes e levá-los a se apropriarem de diversas formas de interação, não podemos ignorar o letramento digital:

Compreendo letramento digital como o conjunto de competências necessárias para que um indivíduo entenda e use a informação de maneira crítica e estratégica, em formatos múltiplos, vinda de variadas fontes e apresentada por meio do computadorinternet, sendo capaz de atingir seus objetivos, muitas vezes compartilhados social e culturalmente. (FREITAS, 2010, p. 339)

O letramento digital, nessa perspectiva, portanto, não está aquém do letramento ideológico, já que este permuta entre todos os letramentos. É interessante notar que o digital é um letramento relativamente novo e a prática social o difundiu de tal maneira que pessoas que não frequentaram a escola conseguem utilizá-lo, mesmo sem ser alfabetizado. Crianças, por exemplo, são exímias usuárias de aplicativos digitais, mesmo antes de iniciarem a vida escolar.

Tal situação assevera o que Rojo (2009, p. 98) diz: "É possível ser não escolarizado e analfabeto, mas participar, sobretudo nas grandes cidades, de práticas de letramento, sendo, assim, letrado de uma certa maneira". As tecnologias estão tão presentes na vida dos indivíduos, principalmente do meio urbano, que não se pode aceitar a crença de que quem ainda não sabe escrever seja iletrado. O letramento, que por si só é múltiplo, intensifica a globalização e pode, em consequência, intensificar a ideologia da cultura dominante.

O letramento autônomo gera exclusão, silencia, torna seres invisíveis. O uso das tecnologias pode tornar essa segregação ainda mais violenta, pois alcança um número muito maior de sujeitos que, se não tiverem a capacidade de refletir e observar criticamente as informações compartilhadas, continuarão reproduzindo os discursos tradicionais de exclusão.

Além dos letramentos acima colocados, a disciplina de Língua Portuguesa em específico deve trabalhar o chamado letramento literário que, segundo Cosson e Souza (2011, p. 102), “é um tipo de letramento singular", pois converte o mundo material em palavras, insere o sujeito 
no mundo da escrita e exige um processo educativo específico que conduza o aluno até a leitura literária. Se o letramento digital é relativamente novo, o literário nos acompanha desde civilizações antigas. Esse letramento não se limita à escrita, uma vez que a literatura também é contada e cantada. Prova disso são os contadores de histórias, cordelistas e pais, resistentes, que insistem em ninar seus filhos contando histórias para dormir.

A literatura carrega consigo todos os letramentos citados anteriormente. Através dela, é possível perceber as diferenças culturais de diferentes sociedades em diferentes épocas e a partir daí inferir as ideologias e relações que levaram e levam a dada situação. As tecnologias também são responsáveis por difundir a literatura. O letramento literário não se limita a saber o enredo de uma história. É, na verdade, "uma experiência de dar sentido ao mundo por meio de palavras, transcendendo os limites do tempo e espaço" (COSSON, SOUZA, 2011, p. 103). O letramento literário proporciona para os alunos o acesso e a reflexão sobre os outros letramentos. Proporciona a imersão em outros mundos a partir da palavra.

\section{O ensino de língua materna e o estudo dos gêneros textuais orais e escritos}

Os letramentos se concretizam por meio dos gêneros textuais, é por meio deles que a linguagem se manifesta e a interação social acontece: “Conhecer os gêneros do discurso é um imperativo se queremos efetivar práticas de letramento em nossa vida. Todo texto que lemos ou produzimos pertence a um determinado gênero" (SILVA, 2011, p. 35).

Gêneros, segundo Bakhtin (1997, p. 279), são “tipos relativamente estáveis de enunciados". Não são, nesse sentido, considerados estruturas cristalizadas que mantêm sempre uma mesma forma. O sujeito, dependendo do seu objetivo e público, escolhe a estrutura que julga mais adequada para cada situação. Daí nascem as práticas comunicativas:

\footnotetext{
Por ser multidimencional, o gênero inclui o textual, o social e o político, devendo ser analisado a partir de diferentes aspectos: formal, retórico, processual e temático. Essas dimensões interagem e se sobrepõe fornecendo ao usuário da língua experiente um conhecimento sofisticado que lhe permite manipulá-los conforme propósitos variados. (OLIVEIRA, 2010, p 337)
}

Ou seja, um sujeito que detém uma gama de gêneros é capaz de utilizá-los manipulando seus aspectos para alcançar seus propósitos. Enquanto professores de Língua Portuguesa, devemos fornecer aos nossos alunos o conhecimento necessário para que possam se apropriar dos letramentos, utilizar os gêneros para modificarem, de alguma forma, suas realidades, bem como exercer a cidadania com consciência do que e como podem fazer. 
Os gêneros do discurso não são isentos de ideologia e, portanto, ao serem trabalhados na escola, o docente não pode exigir "neutralidade" do aluno, nem induzir o aluno a creditar que a neutralidade existe: "Não há ato que realizemos, nem pensamento que exprimamos que não contenha o traço de nosso pertencimento à coletividade" (CHARAUDEAU, 2015, p. 14).

É preciso que o aluno perceba a relação de poder que há ou não em torno de certos letramentos para que utilize seus conhecimentos, imprimindo e valorizando conscientemente sua identidade em suas práticas sociais.

“Os gêneros fazem parte do repertório discursivo dos falantes”, afirma Silva (2010, p. 36). A interação garante que aprendamos a utilizar os gêneros com os quais temos mais contato e esses gêneros passam a fazer parte de nosso repertório. Assim, dependendo da situação, acionamos nosso conhecimento sobre determinado gênero e podemos tanto criar um texto com uma dada intenção quanto prever o gênero que o outro utiliza para se comunicar conosco. Prevemos extensão, intenção e até conclusões.

De acordo com Silva,

Aprendemos a moldar nossa fala às formas do gênero e, ao ouvir a fala do outro, sabemos de imediato, bem nas primeiras palavras, pressentir-lhe o gênero, adivinharlhe o volume (a extensão aproximada do todo discursivo), a dada estrutura composicional, prever-lhe o fim. (SILVA, 2011, p. 35)

Ou seja, desde o início do processo de comunicação o interlocutor através do contexto percebe o gênero que está sendo utilizado e reconhece sua estrutura, objetivo e possível conclusão.

Entendemos que um dos objetivos da educação é levar o discente ao pleno exercício da cidadania em diferentes situações:

Um dos objetivos principais da escola é justamente possibilitar que seus alunos possam participar das várias práticas sociais que se utilizam da leitura e da escrita (letramentos) na vida da cidade, de maneira ética, crítica e democrática. (ROJO, 2009, p. 107)

Os letramentos são imprescindíveis. A nosso ver, a melhor forma de alcançar a maior gama de letramentos possíveis é através do ensino dos gêneros textuais.

O trabalho do professor de língua materna, na forma como desenvolve seu trabalho e seus métodos, está diretamente ligado à sua concepção de linguagem. Segundo Oliveira (2010, p. 342), “diferentes concepções de gênero e de letramento resultam em diferentes práticas”. Por outro lado, a aprendizagem do aluno vincula-se não às suas concepções de linguagem, mas sim aos seus interesses pessoais. Não se aprende simplesmente tudo o que é passado na sala de aula, 
mas aprende aquilo que faz sentido, que tem significado (e o que é importante varia de pessoa para pessoa) e utilidade na vida real. As práticas em sala de aula devem levar em conta também o interesse do aluno. Seria ingenuidade do professor achar que alunos que cursam o Ensino de Jovens e Adultos - EJA, por exemplo, têm os mesmos interesses que os alunos do ensino regular, já que suas expectativas e projeções para o futuro são divergentes, assim como seus interesses. Logo, as práticas de letramentos trabalhadas em sala devem ser diferentes:

Para construir aprendizagem, é necessário levar em conta o contexto e as características individuais, além de criar condições para investir na diversidade (e não na uniformidade), no protagonismo, na construção conjunta de conhecimentos (e não na repetição). (SIMÕES, 2012, p. 14)

Não acreditamos em um ensino neutro, pois toda prática é permeada por questões de manutenção ou questionamento de uma estrutura de poder. Os letramentos usados na escola também servem a algum interesse. O professor, dependendo de suas concepções de letramento, pode ajudar a manter esses interesses ou não. Julgamos, também, que o cidadão consciente questiona e age de forma a modificar estruturas que o mantêm oprimido de alguma forma. Portanto, o ensino deve conscientizar, fazer refletir:

Cabe, portanto, também à escola potencializar o diálogo multicultural, trazendo para dentro de seus muros não somente a cultura valorizada, dominante, canônica, mas também as culturas locais e populares e a cultura de massa, para torná-las vozes de um diálogo, objetos de estudo e de crítica. (ROJO, 2009, p. 115)

O ensino de Língua Materna por meio dos gêneros deve dar ao aprendiz o aparato para perceber como funciona o sistema e assim posicionar-se, de forma passiva ou ativa, mas antes de tudo consciente, diante dele.

Nossos alunos devem se tornar cidadãos plenos. Isso significa "interpretar ativamente o jogo social em que está inserido, o que só pode ser viabilizado pelo acesso aos conteúdos, aos conhecimentos oferecidos pelos vários campos do saber" (SIMÕES, 2012, p. 44).

No caso de Língua Portuguesa, os estudos por meio dos gêneros textuais são uma alternativa para viabilizar o alcance do aluno à cidadania, à percepção da utilidade prática dos letramentos trazidos pela escola. Segundo Oliveira (2010, p. 340), "Os gêneros podem ser objetos de ensino, uma vez que sua apropriação ocorre de modo situado, orientado por propósitos reais". O estudante precisa reconhecer o propósito e a utilidade naquilo que estuda.

Não isolar o trabalho, com diversas práticas sociais nas aulas de Língua Portuguesa, é uma forma de mostrar para o discente que os gêneros têm cada qual o seu propósito. Oliveira (2010) defende a aplicação de projetos, pois os mesmos objetivam a resolução de problemas de forma coletiva: 
Consideramos como uma 'prática de letramento', os projetos que se inserem num tipo de cultura escolar alternativa em que a produção do conhecimento está orientada pela abordagem de 'resolução de problemas', comumente adotada em outras áreas disciplinares. (OLIVEIRA, 2010, p. 340)

O aluno entra na escola já conhecendo a língua, utilizando-a de forma adequada para os ambientes que frequenta. Além disso, já possui o conhecimento de alguns letramentos e gêneros, mesmo sem saber defini-los. O ensino de Língua Portuguesa existe, acreditamos, com o intuito de aprofundar e expandir os conhecimentos do aprendiz, para isso é necessário que nós, professores, tenhamos consciência de como os letramentos são dinâmicos e somente acontecem e se constituem na relação social, na troca de experiências entre os sujeitos, sendo que seus sentidos se alteram a depender de quem os emite e para quem são direcionados.

\section{Considerações finais}

O ensino baseado no letramento autônomo, que aponta para apenas uma mesma direção, fazendo os indivíduos acreditarem que só existe uma forma correta de se expressar e conviver em sociedade, não é mais viável. O perfil do alunado mudou e os discentes não conseguem se adaptar a esse ensino, não mais se conformando em ser meros espectadores dentro de quatro paredes. Eles se mantêm conectados o dia inteiro, praticamente, e se comunicam por meio das redes sociais constantemente. A sala de aula parece ser um local no qual eles não podem manter essa comunicação constante. $\mathrm{O}$ ensino autônomo impõe uma mesma forma de se comunicar adequadamente, de preferência pela escrita, que é "fundamentalmente melhor" que a oralidade, dentro de um padrão cristalizado. Nessa perspectiva, a escrita seria o único letramento que guiaria o sujeito até desenvolvimento intelectual e consequentemente social.

Entretanto acreditamos que os letramentos são múltiplos e diferem de acordo com a prática social comunicativa em que os interlocutores estejam inseridos. Portanto, não é só por meio da escrita que esses ideais (racionalidade, isenção e objetividade) podem ser alcançados, já que a oralidade também tem essa característica. É evidente que, para quem vive em uma sociedade que supervaloriza a escrita, ter domínio sobre esse letramento é importante, principalmente para que o indivíduo não seja excluído do convívio social. Na escola que se utiliza do modelo autônomo, a língua é tratada com distanciamento, como se fosse algo externo aos alunos. 
Enquanto profissionais que promovem educação, temos o dever de esclarecer nossa clientela acerca desse jogo de poder que separa os indivíduos entre "letrados" (bem-sucedidos) e "iletrados" (invisíveis). A partir de então, devemos dar-lhes ferramentas para perceberem e agirem diante dessa conjuntura.

Defendemos que o ensino de Língua Materna que utiliza os gêneros textuais como ferramenta para se alcançar os diversos letramentos é uma forma eficaz de se combater o letramento autônomo. Como sugere Oliveira, por meio dos gêneros textuais se pode trabalhar projetos de letramentos que envolvem a transdisciplinaridade em eventos situados de aprendizagem.

Portanto, os projetos de letramentos são uma boa opção para trabalhar os gêneros textuais e assim alcançar uma diversidade de letramentos em diversas áreas do conhecimento, possibilitando aos nossos alunos uma visão mais ampla da real necessidade dos letramentos utilizados na escola.

Em nossa pesquisa, os alunos vão produzir uma reportagem sobre algum acontecimento de sua realidade biossocial. Primeiramente, os alunos vão fazer a coleta de dados com algumas anotações e leitura de textos de gêneros diversos. Faremos ainda debates que serão produzidos em parceria com outros docentes da Unidade de Ensino e, com vistas à interdisciplinaridade, vamos proporcionar os diálogos (roda de conversa ,entrevistas com colegas, pais e/ou profissionais da escola). Acreditamos que os alunos vão compreender e refletir criticamente acerca dos discursos que são enunciados nesses eventos, de modo que se tornem críticos em relação aos discursos que emergem no contexto local e textos escritos.

\section{Referências}

ANTUNES, Irandé. A língua e a identidade cultural de um povo. In: Língua, texto e ensino: outra escola possível. São Paulo: Parábola Editorial, 2009.

BAKHTIN, Mikhail M. Estética da criação verbal. São Paulo: Martins Fontes, 1997.

BRASIL, Constituição (1988). Constituição da República Federativa do Brasil. Brsília, DF: Senado Federal: Centro gráfico, 2018. 292p.

BRONCKART, Jean-Paul. Quadro e questionamento epistemológico In: Atividade de linguagem, textos e discursos: por um interacionismo sócio-discursivo. São Paulo: EDUC, 1999. 
CARNEIRO, Edilson. Singularidades dos quilombos. In: MOURA, Clovis. Os quilombos na dinâmica social do Brasil. Maceió: EDUFAL, 2001.

CHARAUDEAU, Patrick. Identidade lingüística, identidade cultural: uma relação paradoxal. In: LARA, Glaucia P. LIMBERT, Rita P. (Org.). Discurso e (des)igualdade social. São Paulo: Contexto, 2015.

FREITAS, Maria T. Letramento digital e a formação de professores. Educação em Revista. Belo Horizonte, v. 26, n. 03, p. 335-352, dez. 2010.

LARA, Glaucia P. LIMBERT, Rita P. (Org.). Discurso e (des)igualdade social. São Paulo: Contexto, 2015.

LARCHERT, Jeanes M. Oliveira, Maria W. de. Panorama da educação quilombola no Brasil. Políticas Educativas. Porto Alegre, v. 6, n. 2, p. 44-60, 2013.

OLIVEIRA, Maria do S. Gêneros textuais e letramento. RBLA. Belo Horizonte, v. 10, n. 2, p. 325-345, 2010.

PARÁ. Conselho Estadual de Educação. Resolução $n^{\circ} 001$ de 05 de janeiro 2010. Disponível em:http://www.cee.pa.gov.br/sites/default/files/RESOLUCAO_001_2010_REGULAMENTA CAO_EDUC_BAS-1.pdf

ROJO, Roxane. Letramentos múltiplos, escola e inclusão social. São Paulo: Parábola Editorial, 2009.

SILVA, Vanessa S. da. Letramento e ensino de gêneros. Educ. Foco. Juiz de Fora, v. 16, n. 1, p. 19-40, ago. 2011.

SIMÕES, Luciene Juliano. Leitura e autoria: planejamento em língua portuguesa e literatura. Erechim: Edelbra, 2012.

SOUZA, Renata J. de. Cosson, Rildo. Letramento literário: uma proposta para a sala de aula. Caderno de formação de professores, didática de conteúdos, São Paulo: Cultura, v. 2, p. 101$108,2001$.

STREET, Brian V. Letramentos sociais: abordagens críticas do letramento no desenvolvimento, na etnografia e na educação. São Paulo: Parábola Editorial, 2014.

Recebido em 04 de setembro de 2018. Aceito em 26 de outubro de 2018 